\title{
The Effect of Comprehensive Video-Assisted Epilepsy Education on Drug Adherence and Self-Care in People with Epilepsy
}

\author{
Arul Jothi ${ }^{1} \quad$ Lakshmi Ramamoorthy ${ }^{2}$ Pradeep P. Nair ${ }^{3}$ \\ ${ }^{1}$ College of Nursing, Jawaharlal Institute of Post Graduate Medical \\ Education and Research (JIPMER), Puducherry, India \\ ${ }^{2}$ College of Nursing, Jawaharlal Institute of Postgraduate Medical \\ Education and Research (JIPMER), Puducherry, India

\begin{abstract}
Address for correspondence Lakshmi Ramamoorthy, MSc, PhD, College of Nursing, Jawaharlal Institute of Post Graduate Medical Education and Research (JIPMER), Puducherry, Tamil Nadu, India (e-mail: laxmi_ramamoorthy@yahoo.com).
\end{abstract}

${ }^{3}$ Department of Neurology, Jawaharlal Institute of Postgraduate Medical Education and Research (JIPMER), Puducherry, India

J Neurosci Rural Pract 2020;11:538-544

\begin{abstract}
Background Epilepsy is a chronic neurological disorder which needs proper drug adherence and follow-up care to control the recurrent seizure events as one of the most common reasons for "breakthrough" seizures is nonadherence to antiepileptic drugs. In addition to usual therapeutic management, patients are encouraged to involve in epilepsy self-management by understanding the nature of the disease and its control measures to prevent the complications.

Methods A single group experimental design (pretest-posttest) was conducted to evaluate the effect of comprehensive video-assisted teaching program on self-care efficacy and level of knowledge of patients with epilepsy. Data was collected by direct interview with Epilepsy Self-Management Scale and epilepsy knowledge questionnaire. A video-assisted teaching covering all aspects of epilepsy was given on the day of pretest. At the interval of 3 months, the level of drug adherence, self-care, and knowledge level were assessed.

Results Majority of the study participants (47.1\%) belonged to the age group between 19 and 30 years, $54.3 \%$ participants were male, majority of them (70\%) had tonic-clonic seizure, and $40 \%$ of them reported the onset of seizures as above 20 years. Eighty-seven percent of participants had no family history of seizures or epilepsy. Note that $38.6 \%$ of the participants had at least one seizure episode/month. Majority of the caregivers were either parents $(41.4 \%$ ) or spouse $(48.6 \%)$. The study revealed that, following video-assisted teaching, the proportion of participants with adequate knowledge has increased from 14 to $64.3 \%$. Similarly, the percentage of participants who had good drug adherence increased from 52 to $65 \%$ and no participant had poor drug

Keywords

- epilepsy

- follow-up

- neurology adherence. Participants who had high level of self-care increased from 71.4 to $88.6 \%$. Conclusion To overcome the poor drug adherence-related complications, people with epilepsy are to be personally educated adequately to increase the factual information about the condition and their self-care practices.
\end{abstract}

\section{Introduction}

Among common neurological disorders, seizure disorder shares approximately $1 \%$ of the total burden of disease worldwide; out of which, more than three-quarters of the population live in low to lower middle income countries. In India, approximately 10 to 12 million people suffer from epilepsy. ${ }^{1,2}$ Epilepsy is a disorder of chronic, frequent seizures in which the onset and duration of the seizure cannot be anticipated. This common disease have a notable social 
stigma which leads to discrimination in the society which further disable the self-esteem of people with epilepsy. Societal stigma often caused by misconceptions, myths, and misunderstandings about the disease have been observed for thousands of years. ${ }^{3,4}$ Social discrimination often leads to reduced interest to access medical care, and many of them try to hide their disease in view of negative stereotyping., ${ }^{5,6}$ A range of incorrect and even harmful practices to regulate seizure are frequently embraced; for instance, keeping iron rod in the hand, rubbing irritants to eyes, holding the patient in fire, burns, and ingestion of cow urine..$^{7-9}$ It is imperative to educate about management of this chronic disease to the caregivers and patients with epilepsy to improve self-care. ${ }^{10-12}$

Persons with seizure disorder need to transform their lifestyle primarily focusing on drug adherence and selfcare. Modification of the lifestyle and adhering to treatment regime is key for improving their quality of life. Hence, this study is focused to evaluate the self-care management educational program with the support of video, focused on disease characteristics, monitoring symptoms, management modalities, significance of drug adherence, and managing lifestyle pattern to increase patient's self-confidence by improving their understanding about the disease.

\section{Methods}

A single group experimental design (pretest-posttest) was applied to evaluate the effect of comprehensive video-assisted teaching program on self-care efficacy and level of knowledge among patients with seizure disorder. Participants who were in the age group of 18 to 65 years, who were enrolled in the institute's epilepsy clinic were included in the study. Sample size estimated was 70 with power of the study as $90 \%$ and $5 \%$ level of significance. It was calculated based on mean difference in drug adherence score before and after implementation of education program as 6.58 versus $7.53 .^{7}$ Consecutive sampling technique was used. Under Graduate Research Monitoring Committee and Institute Ethical Committee approval was obtained (JIP/IEC/2018/111).

With the help of epilepsy knowledge questionnaire and Epilepsy Self-Management Scale (ESMS), the data was collected by interview method. The ESMS has five domains which focus on safety management, medication management, seizure management, and lifestyle management. The internal consistency reliability was 0.81 to $0.86 .{ }^{13}$ The epilepsy knowledge questionnaire has 20 items about the knowledge of epilepsy. The score ranges from 0 to 20; the higher the score, the higher the knowledge level.

A video-assisted teaching covering all aspects of epilepsy was given to the people with epilepsy on the day of pretest. At an interval of 3 months, the level of drug adherence, selfcare, and knowledge level were assessed.

The continuous data such as age, duration of treatment, number of seizure per last month, number of drugs, and frequency of the drugs was expressed as mean with standard deviation or median with range, whereas the distribution of nominal data including literacy, occupation status, participants' gender, marital status, domicile status, and comorbidity history was stated as frequency and percentages. Chi-square/Fisher's exact test was used to analyze the level of drug adherence with sociodemographic characteristics. ESMS domains and knowledge score before and after implementation of video-assisted teaching program was analyzed with paired $t$-test. The level of statistical significance $p<0.05$ was considered as significant.

\section{Results}

Results showed $47.1 \%$ of the participants belonged to the age group between 19 and 30 years, 54.3\% participants were male, $7.1 \%$ were illiterate, and majority of the participants (82.9\%) were from rural ( - Table $\mathbf{1})$.

Majority of the participants (70\%) had generalized tonic-clonic seizure, $40 \%$ of the participants had the age of onset of seizures at above 20 years, $87 \%$ of participants had no family history of seizures or epilepsy. Note that $38.6 \%$ of the participants had at least one seizure episode/month. Majority of the caregivers were either parents $(41.4 \%)$ or spouse $(48.6 \%$ ) ( - Table 2 ).

- Table 3 shows the pre- and postintervention mean score and standard deviation for the level of knowledge of people with epilepsy who had undergone the educational program (video-assisted epilepsy education). It shows during pretest $12(17.1 \%)$ of the participants had inadequate knowledge regarding epilepsy, 48 (68\%) participants had moderate level of knowledge, and 10 (14.3\%) participants had adequate knowledge. During posttest, 45 (64.3\%) had adequate knowledge, 23 (35.7\%) had moderate knowledge, and no participants had inadequate knowledge.The level of good drug adherence of people with epilepsy improved to $65 \%$ from $52 \%$ and no participant had poor drug adherence after receiving the video-assisted teaching. Similarly, the percentage of participants who had high level of self-care increased from 71.4 to $88.6 \%$ (-Tables 4 and $\mathbf{5}$ ). Various sub domain mean score of Epilepsy Self-Management Scale (ESMS) also improved following video-assisted education ( - Table 6 ).

\section{Discussion}

\section{Sociodemographic and Seizure Characteristics}

This study included 70 epilepsy patients with the mean age of $33.54 \pm 11.22$ years. Majority of the study participants (54.4\%) were male and $38.6 \%$ of the participants had at least one seizure episode per month. Note that $7.1 \%$ had comorbidities like diabetes mellitus, hypertension, and hypothyroidism. Similar mean age of participants with seizures, and male preponderance has also been observed in earlier studies..$^{10,11}$

The average age of onset of seizure was 18 years with $7.1 \%$ of the participants suffering day time seizures. Seventy percent of them were in the category of tonic-clonic seizure. In a comparable study by Hovinga et al, it was reported that among 408 participants, the average mean age of onset was 20 years, and majority of them (57\%) were reported with tonic-clonic seizures and $12 \%$ had day time seizure. ${ }^{13,14}$ 
The Effect of Comprehensive Video-Assisted Epilepsy Education on Drug Adherence and Self-Care in

Table 1 Sociodemographic characteristics $(N=70)$

\begin{tabular}{|c|c|c|c|c|}
\hline Sociodemographic characteristics & Frequency $(n)$ & Percentage (\%) & Chi-square & $p$-Value \\
\hline \multicolumn{5}{|l|}{ Age (in y) } \\
\hline $19-30$ & 33 & 47.1 & \multirow[t]{3}{*}{15.457} & \multirow[t]{3}{*}{0.000} \\
\hline $31-45$ & 29 & 41.4 & & \\
\hline $46-65$ & 8 & 11.4 & & \\
\hline \multicolumn{5}{|l|}{ Mean age: $33.54 \pm 11.22 \mathrm{y}$} \\
\hline \multicolumn{5}{|l|}{ Sex } \\
\hline Male & 38 & 54.3 & \multirow[t]{2}{*}{0.514} & \multirow[t]{2}{*}{0.473} \\
\hline Female & 32 & 45.7 & & \\
\hline \multicolumn{5}{|l|}{ Education } \\
\hline Illiterate & 5 & 7.1 & \multirow[t]{5}{*}{14.286} & \multirow[t]{5}{*}{0.006} \\
\hline Primary & 24 & 34.3 & & \\
\hline High school & 17 & 24.3 & & \\
\hline Higher secondary & 13 & 18.6 & & \\
\hline Graduate & 11 & 15.7 & & \\
\hline \multicolumn{5}{|l|}{ Occupation } \\
\hline Unemployed & 6 & 8.6 & \multirow[t]{4}{*}{31.143} & \multirow[t]{4}{*}{0.000} \\
\hline House wife & 23 & 32.9 & & \\
\hline Agriculture & 7 & 10.0 & & \\
\hline Employed & 34 & 48.6 & & \\
\hline \multicolumn{5}{|l|}{ Income (INR) } \\
\hline Less than 1,000 & 5 & 7.1 & \multirow[t]{3}{*}{96.200} & \multirow[t]{3}{*}{0.000} \\
\hline $1,000-2,000$ & 62 & 88.6 & & \\
\hline More than 2,000 & 3 & 4.3 & & \\
\hline \multicolumn{5}{|l|}{ Marital status } \\
\hline Married & 51 & 72.9 & \multirow[t]{2}{*}{14.629} & \multirow[t]{2}{*}{0.000} \\
\hline Unmarried & 19 & 27.1 & & \\
\hline \multicolumn{5}{|l|}{ Domicile } \\
\hline Rural & 58 & 82.9 & \multirow[t]{2}{*}{30.229} & \multirow[t]{2}{*}{0.000} \\
\hline Urban & 12 & 17.1 & & \\
\hline
\end{tabular}

Approximately more than half of patients in this study were on polytherapy. Similar proportions were found in other studies also. ${ }^{15,16}$

\section{Level of Knowledge on Epilepsy}

In the current study, the mean knowledge score of the participants increased from $10.82 \pm 3.93$ to $15 \pm 2.59$ following video-assisted education during posttest which was significant at $(p=0.000)$. The number of participants with adequate level of knowledge increased from 10 (14.3\%) to $45(63.3 \%)$ after the implementation of the video-assisted epilepsy education. In a related study led by May et al, it was observed that the knowledge level improved after the educational treatment and was significant $(p<0.001) .{ }^{15}$

\section{Drug Adherence and Self-Care}

Patients' knowledge on disease management is directly proportionate to their disease outcome, satisfaction, and quality of life. Educating patients and their caregivers in epilepsy is an important component of quality management, including improving self-care outcomes and overall epilepsy care. The pretest mean score of the participants for the level of drug adherence were $39.34 \pm 7.015$, during posttest it was $45.40 \pm 5.417$ which was highly significant $(p=0.000)$. The number of participants with good level of drug adherence increased from 52 (74.3\%) to 65 (92.9\%) after the implementation of the video-assisted teaching program which was concurrent with the studies. Frequency of the drugs per day (patients with monotherapy) associated significantly with the level of drug adherence with a $p$-value of 0.010 . 
Table 2 Seizure characteristics $(N=70)$

\begin{tabular}{|c|c|c|c|c|}
\hline Seizure characteristics & $\begin{array}{l}\text { Frequency } \\
(n)\end{array}$ & $\begin{array}{l}\text { Percentage } \\
(\%)\end{array}$ & Chi-square & $p$-Value \\
\hline \multicolumn{5}{|l|}{ Type of seizure } \\
\hline Generalized tonic-clonic seizure & 49 & 70 & \multirow[t]{5}{*}{116.286} & \multirow[t]{5}{*}{0.000} \\
\hline Complex partial seizure & 6 & 8.6 & & \\
\hline Absence seizure & 1 & 1.4 & & \\
\hline Myoclonic seizure & 1 & 1.4 & & \\
\hline Others & 3 & 18.6 & & \\
\hline \multicolumn{5}{|l|}{ Age of onset } \\
\hline Before 5 y & 15 & 21.4 & \multirow[t]{4}{*}{9.200} & \multirow[t]{4}{*}{0.027} \\
\hline $6-12 y$ & 11 & 15.7 & & \\
\hline $13-20 y$ & 16 & 22.9 & & \\
\hline After $20 \mathrm{y}$ & 28 & 40.0 & & \\
\hline \multicolumn{5}{|l|}{ Mean age of onset: $18.81 \pm 13.14 \mathrm{y}$} \\
\hline \multicolumn{5}{|l|}{ Family history } \\
\hline Yes & 9 & 12.9 & \multirow[t]{2}{*}{38.629} & \multirow[t]{2}{*}{0.000} \\
\hline No & 61 & 87.1 & & \\
\hline \multicolumn{5}{|l|}{ Duration of treatment } \\
\hline Less than $5 \mathrm{y}$ & 32 & 45.7 & \multirow[t]{3}{*}{5.171} & \multirow[t]{3}{*}{0.075} \\
\hline $6-10 y$ & 17 & 24.3 & & \\
\hline More than $10 \mathrm{y}$ & 21 & 30.0 & & \\
\hline \multicolumn{5}{|l|}{ No of drugs per day } \\
\hline One drug & 29 & 41.4 & \multirow[t]{4}{*}{33.086} & \multirow[t]{4}{*}{0.000} \\
\hline Two drugs & 29 & 41.4 & & \\
\hline Three drugs & 11 & 17.7 & & \\
\hline More than three drugs & 1 & 1.4 & & \\
\hline \multicolumn{5}{|l|}{ Drug resistant epilepsy } \\
\hline No & 70 & 100 & - & - \\
\hline \multicolumn{5}{|l|}{ Frequency of drugs per day } \\
\hline 1 time & 5 & 7.1 & \multirow[t]{3}{*}{26.429} & \multirow[t]{3}{*}{0.000} \\
\hline 2 times & 25 & 35.7 & & \\
\hline 3 times & 40 & 57.1 & & \\
\hline \multicolumn{5}{|l|}{ No of seizure per last month } \\
\hline No seizure & 27 & 38.6 & \multirow[t]{5}{*}{31.571} & \multirow[t]{5}{*}{0.000} \\
\hline One seizure & 22 & 31.4 & & \\
\hline 2 seizures & 13 & 18.6 & & \\
\hline 3 seizures & 6 & 8.6 & & \\
\hline More than 3 times & 2 & 2.9 & & \\
\hline \multicolumn{5}{|l|}{ Usual time of seizure occurrence } \\
\hline Day time & 5 & 7.1 & 47.857 & 0.000 \\
\hline Night time & 15 & 21.4 & & \\
\hline No specific time & 50 & 71.4 & & \\
\hline Caregiver & & & & \\
\hline Parents & 29 & 41.4 & 17.686 & 0.000 \\
\hline Spouse & 34 & 48.6 & & \\
\hline Others & 7 & 10.0 & & \\
\hline
\end{tabular}


The Effect of Comprehensive Video-Assisted Epilepsy Education on Drug Adherence and Self-Care in

People with Epilepsy Jothi et al.

Table 2 (Continued)

\begin{tabular}{|c|c|c|c|c|}
\hline Seizure characteristics & Frequency $(n)$ & Percentage (\%) & Chi-square & $p$-Value \\
\hline \multicolumn{5}{|l|}{ Comorbidity } \\
\hline No & 65 & 92.9 & \multirow[t]{2}{*}{51.429} & \multirow[t]{2}{*}{0.000} \\
\hline Yes & 5 & 7.1 & & \\
\hline \multicolumn{5}{|l|}{$\mathrm{CT} / \mathrm{MRI}$ findings } \\
\hline No changes & 62 & 88.6 & \multirow[t]{9}{*}{41.657} & \multirow[t]{9}{*}{0.000} \\
\hline Changes & 8 & 11.4 & & \\
\hline Hypodensity in frontal lobe & 1 & 1.4 & & \\
\hline Parietal lobe calcification & 2 & 2.8 & & \\
\hline Frontal lobe calcification & 1 & 1.4 & & \\
\hline Ischemic vessel changes & 1 & 1.4 & & \\
\hline Small size of right hippocampus & 1 & 1.4 & & \\
\hline Right temporal horn prominence & 1 & 1.4 & & \\
\hline Right mesotemporal sclerosis & 1 & 1.4 & & \\
\hline \multicolumn{5}{|l|}{ EEG findings } \\
\hline No changes & 69 & 98.6 & \multirow[t]{2}{*}{66.057} & \multirow[t]{2}{*}{0.000} \\
\hline Epileptoform activity & 1 & 1.4 & & \\
\hline
\end{tabular}

Abbreviations: CT, computed tomography; EEG, electroencephalogram; MRI, magnetic resonance imaging.

Table 3 Knowledge on epilepsy $(N=70)$

\begin{tabular}{|c|c|c|c|c|c|c|c|}
\hline \multirow[t]{2}{*}{ Knowledge } & \multicolumn{3}{|c|}{ Pretest } & \multicolumn{3}{|c|}{ Posttest } & \multirow[t]{2}{*}{$p$-Value } \\
\hline & Frequency $(n)$ & Percentage (\%) & $p$-Value & Frequency $(n)$ & Percentage (\%) & $p$-Value & \\
\hline Inadequate & 12 & 17.1 & 0.000 & - & - & 0.017 & 0.000 \\
\hline Moderate & 48 & 68.6 & & 25 & 35.7 & & \\
\hline Adequate & 10 & 14.3 & & 45 & 64.3 & & \\
\hline Total & 70 & 100 & & 70 & 100 & & \\
\hline Mean & \multicolumn{2}{|c|}{10.8286} & & \multicolumn{2}{|c|}{15.000} & & \\
\hline $\begin{array}{l}\text { Standard } \\
\text { deviation }\end{array}$ & \multicolumn{2}{|c|}{3.93414} & & \multicolumn{2}{|c|}{2.59004} & & \\
\hline
\end{tabular}

Table 4 Level of drug adherence $(N=70)$

\begin{tabular}{|c|c|c|c|c|c|c|c|}
\hline \multirow{2}{*}{$\begin{array}{l}\text { Level of drug } \\
\text { adherence }\end{array}$} & \multicolumn{3}{|c|}{ Pretest } & \multicolumn{3}{|c|}{ Posttest } & \multirow[t]{2}{*}{$p$-Value } \\
\hline & Frequency $(n)$ & Percentage (\%) & $p$-Value & Frequency $(n)$ & Percentage (\%) & $p$-Value & \\
\hline Poor & 1 & 1.4 & 0.000 & - & - & 0.000 & 0.000 \\
\hline Average & 17 & 24.3 & & 5 & 7.1 & & \\
\hline Good & 52 & 74.3 & & 65 & 92.9 & & \\
\hline Total & 70 & 100 & & 70 & 100 & & \\
\hline Mean & \multicolumn{2}{|c|}{39.34} & & \multicolumn{2}{|c|}{45.40} & & \\
\hline $\begin{array}{l}\text { Standard } \\
\text { deviation }\end{array}$ & \multicolumn{2}{|c|}{7.015} & & \multicolumn{2}{|c|}{5.417} & & \\
\hline
\end{tabular}


Table 5 Self-care level $(N=70)$

\begin{tabular}{|c|c|c|c|c|c|c|c|}
\hline \multirow{2}{*}{$\begin{array}{l}\text { Self-care } \\
\text { level }\end{array}$} & \multicolumn{3}{|c|}{ Pretest } & \multicolumn{3}{|c|}{ Posttest } & \multirow[t]{2}{*}{$p$-Value } \\
\hline & Frequency $(n)$ & Percentage (\%) & $p$-Value & Frequency $(n)$ & Percentage (\%) & $p$-Value & \\
\hline Low & - & - & 0.000 & - & - & 0.000 & 0.002 \\
\hline Average & 20 & 28.6 & & 8 & 11.4 & & \\
\hline High & 50 & 71.4 & & 62 & 88.6 & & \\
\hline Total & 70 & 100 & & 70 & 100 & & \\
\hline Mean & \multicolumn{2}{|c|}{130} & & \multicolumn{2}{|c|}{154} & & \\
\hline $\begin{array}{l}\text { Standard } \\
\text { deviation }\end{array}$ & \multicolumn{2}{|c|}{15.893} & & \multicolumn{2}{|c|}{19.114} & & \\
\hline
\end{tabular}

Table 6 Self-care domains $(N=70)$

\begin{tabular}{|l|l|l|l|l|l|}
\hline & \multicolumn{2}{|c|}{ Pretest } & \multicolumn{3}{c|}{ Posttest } \\
\hline Self-care domains & Mean & Standard deviation & Mean & Standard deviation & $p$-Value \\
\hline $\begin{array}{l}\text { Medication } \\
\text { management }\end{array}$ & 39.34 & 7.01 & 45.4 & 5.41 & 0.000 \\
\hline $\begin{array}{l}\text { Information } \\
\text { management }\end{array}$ & 22.28 & 7.92198 & 24.87 & 5.81 & 0.000 \\
\hline Self-management & 28.21 & 4.21 & 32.10 & 4.585 & 0.000 \\
\hline Seizure management & 23.13 & 5.464 & 25.00 & 4.700 & 0.000 \\
\hline Lifestyle management & 17.63 & 4.69 & 20.31 & 5.199 & 0.533 \\
\hline
\end{tabular}

Dash et al have shown similar results where the level of drug adherence was increased after epilepsy health education $(p<0.001)$. The pretest mean score (ESMS) of the participants for the level of self-care was $130 \pm 15.89$, during posttest it was $154 \pm 19.11$ which was significant $(p=0.002){ }^{7}$ In the present study, the number of participants with high level of self-care increased from 50 (71.4\%) to 62 (88.6\%) after implementation of the video-assisted teaching program which was concurrent with the previous studies. In a comparable study, which showed similar results, the mean score of self-care increased from $2.97 \pm 0.11$ to $3.39 \pm 0.15$ after epilepsy education and was significant $(p=0.0005) .{ }^{16}$

\section{Conclusion}

Educational program to the people with epilepsy is the need of the hour to enhance awareness about disease management and self-care which would improve the outcome of the treatment regimen. Further, this kind of programs helps the patient and their caregivers to overcome the myth and prejudiced lifestyle practices related with this chronic disease. The present study demonstrates that video-assisted epilepsy education improves the knowledge, drug adherence, and self-care in people with epilepsy.

\section{Funding}

Short term Research award of INR 10,000 was recieved from Jawaharlal Institute of Post Graduate Medical
Education and Research (JIPMER), Puducherry for this project.

\section{Conflict of Interest}

None declared.

\section{References}

1 World Health Organization, Atlas: Epilepsy Care in the World. Geneva, Switzerland: WHO; 2005

2 Paul P, Agarwal M, Bhatia R, Vishnubhatla S, Singh MB. Nurseled epilepsy follow-up clinic in India: is it feasible and acceptable to patients? A pilot study. Seizure 2014;23(1):74-76

3 Ibinda F, Mbuba CK, Kariuki SM, et al. Evaluation of Kilifi epilepsy education programme: a randomized controlled trial. Epilepsia 2014;55(2):344-352

4 Das AM, Ramamoorthy L, Narayan SK, Wadwekar V. Barriers of drug adherence among patients with epilepsy: in tertiary care hospital, South India. J Caring Sci 2018;7(4):177-181

5 Baybaş S, Yıldırım Z, Ertem DH, Dirican A, Dirican A. Development and validation of the stigma scale for epilepsy in Turkey. Epilepsy Behav 2017;67:84-90

6 Goel S, Singh N, Lal V, Singh A. Evaluating the impact of comprehensive epilepsy education programme for school teachers in Chandigarh city, India. Seizure 2014;23(1):41-46

7 Dash D, Sebastian TM, Aggarwal M, Tripathi M. Impact of health education on drug adherence and self-care in people with epilepsy with low education. Epilepsy Behav 2015;44:213-217

8 Jansen P, Neininger MP, Bernhard MK, et al. Knowledge and attitudes about epilepsy: a survey of high school students in Germany. Seizure 2017;51:139-144 
People with Epilepsy Jothi et al.

9 Singh AJ, Arora AK. Knowledge, attitude and practices of relatives of epileptics towards epilepsy. Nurs Midwifery Res J 2005;1:77-81

10 Yang A, Wang B, Zhu G, et al. Validation of Chinese version of the Morisky medication adherence scale in patients with epilepsy. Seizure 2014;23(4):295-299

11 Aliasgharpour M, Dehgahn Nayeri N, Yadegary MA, Haghani $\mathrm{H}$. Effects of an educational program on self-management in patients with epilepsy. Seizure 2013;22(1):48-52

12 Tang F, Zhu G, Jiao Z, Ma C, Chen N, Wang B. The effects of medication education and behavioral intervention on Chinese patients with epilepsy. Epilepsy Behav 2014;37:157-164

13 Dilorio C, Faherty B, Manteuffel B. Self-efficacy and social support in self-management of epilepsy. West J Nurs Res 1992;14(3):292-303, discussion 303-307
14 Hovinga CA, Asato MR, Manjunath R, et al. Association of non-adherence to antiepileptic drugs and seizures, quality of life, and productivity: survey of patients with epilepsy and physicians. Epilepsy Behav 2008;13(2):316-322

15 May TW, Pfäfflin M; Modular Service Package Epilepsy. The efficacy of an educational treatment program for patients with epilepsy (MOSES): results of a controlled, randomized study. Epilepsia 2002;43(5):539-549

16 Seethalakshmi A, Shankar V, Samson R. Effectiveness on epilepsy education programme on self-management among patients with Epilepsy. IOSR-JNHS 2015;4:35-41 